AIRTON PASCHOA

Casa-grande

\& grande-sertão

num conto de

Guimarães Rosa

(ensaio de

interpretação) 


\section{AIRTON PASCHOA}

é escritor, autor, entre outros, de Contos Tortos (Nankin).



s grandes questões históricas, nacionais, políticas, econômicas, sociais, etc. não são apanágio exclusivo do romance, nem dos escritores ditos realistas. Elas contaminam também as formas breves e perseguem narradores avessos, em princípio, ao realismo mais chão, ou às palavras de ordem mais candentes do tempo. Este é o caso de um conto de Guimarães Rosa, das Primeiras Estórias, de 1962.

O título do conto, "Nada e a Nossa Condição", aparentemente filosófico, existencialista, indica logo seu caráter exemplar; trata-se da condição humana; só que esta exemplaridade será dada por um destino rústico quase cifrado, um destino que caberá interpretar, e que, diferentemente de um Riobaldo do Grande Sertão: Veredas, por exemplo, não nos oferece sequer uma versão dele.

O nosso personagem, Tio Man'Antônio (é o sobrinho quem conta sua história), mal fala, e quando o faz, nas poucas vezes em que isso ocorre, roça o esfíngico: "Lá em casa... Vou para casa..."; "Faz de conta, minha filha... Faz de conta...”; “Faça-se de conta!"; "Nem tanto, filha... Nem tanto..." - tais as orações reticentes, lacônicas e lacunares, pronunciadas sempre no mesmo diapasão, como a compor uma fala essencial, oracular.

À semelhança da fala, são verdadeiramente enigmáticos os gestos de Tio Man'Antônio, gestos, aliás, em aparência, completamente desarrazoados, próprios, quando vistos a distância, de um louco ("A tento, amiúde, distinguir-se-iam mesmo seus omissos gestos principais: o de, vem em vez, fazer que afastava, devagar, de si, quaisquer coisas").

"Destinado", enigmático, cifrado em sua conduta e em sua expressão, esse personagem que, do fundo de seu abismo, murmura Shakespeare, “coisas graves, grandes, sem som nem sentido”, esse personagem carrega ainda uma culpa indefinível e uma vaga esperança, cumprindo um verdadeiro ritual de purgação.

\section{UMA MONTANHA DE QUESTÕES}

À primeira leitura do conto, e de sua primeira parte, especialmente, a parte prénarrativa, que antecede a morte de Tia Liduína, a qual desencadeia a metamorfose do viúvo, vamos acumulando questão sobre questão:

- uma fazenda comprada no fim do mundo... por quê?

- um homem "individido e esquivo"... por quê? teria algo a encobrir? estaria se escondendo de alguma coisa, ele, de cujo passado "muita real coisa ninguém sabia"? - uma casa-grande infanda (“jamais quase a referisse pelo nome”), que não se deve nomear... por quê? por que esse mal-estar ao adentrá-la? por que não se sentia bem nela, tão boa, tão dada e avarandada?

- esse vestir-se "em grau de reles libré”... por quê? seria o último homem de uma casa nobre?

- e que pensar desses seus “omissos gestos principais", afastando de si alguma coisa invisível mas tangível, e que tanto o incomodava?

- e a paisagem, então? porque contemplála tanto, a ponto de quase perder a vista?

- por que essa necessidade de admirar a assombrosa paisagem, seus “cumes e fundos"?

- por que esse ritual de "esperança e expiação”, esse subir e descer sem fim, atravessando "caminhos fragosos, à beira de despenhadeiros e crevassas - grotas de tremenda altura [...] abismáticas, profun- 
díssimas", agüentando "sequidão, solidão, calor e frio"?

- qual a razão enfim - eis a intriga maior - desse purgatório, visto que a topografia de sua montanha ("Da varanda, dado o dia diáfano, já ainda a distância de tanto e légua avistavam-no, pontuando o claro do ar, em certas voltas de estrada, a aproximar-se e desaproximar-se, sequer seqüente") reproduz a montanha em espiral do Purgatório de Dante?

- por que deve ser este homem, melhor dizendo, este "Destinado" em que se convertera ele ao final de seu percurso, por que deve ser, retornando ao título do conto, um exemplo da "nossa condição"?

Resumindo, estamos diante de um conto com pretensão exemplar, plasmado num tom fabuloso, e protagonizado por uma personagem esfíngica, quase sobre-humana, que vive a expiar uma culpa indefinível, nutrindo uma vaga esperança.

Se atentamos porém ao cenário extraordinariamente sugestivo que descreve Guimarães Rosa, uma casa-grande nos confins do mundo e no alto de uma montanha, uma casa-grande, de um lado, símbolo de nosso passado colonial, com todo o seu peso histórico ainda sensível, e, de outro lado, uma paisagem fascinante e misteriosa, um grande-sertão mágico e "lendário" (1), com todo o seu apelo sobrenatural, e no meio, premido, um homem esquivo e visionário, a cumprir um ritual de expiação e esperança, começa a despontar uma chave explicativa.

Em oposição ao grande-sertão, a sua descrição fantasmagórica, em oposição à caracterização conto-de-fada do próprio personagem ("homem de mais excelência que presença, que podia ter sido o velho rei ou o príncipe mais moço nas futuras estórias de fadas"), crescia uma casa-grande pintada em cores quase realistas:

“À que - assobradada, alicerçada fundo, de tetos altos, longa, e com quantos sem uso corredores e quartos, cheirando a fruta, flor, couro, madeiras, fubá fresco e excremento de vaca - fazia face para o norte, entre o quintal de limoeiros e os currais, que eram um ornato; e, à frente, escada de pau de quarenta degraus em dois lanços levava ao espaço da varanda, onde, de um caibro, a um canto, pendia ainda a corda do sino de outrora comandar os escravos assenzalados".

Esta casa-grande, descrita com tanto realismo, a ponto de quase sentirmos seus odores inconfundíveis, podia agora explicar os "omissos gestos principais" de Tio Man’ Antônio, seu como que afastar qualquer coisa de si, repugnado; seu incômodo ao adentrá-la; sua impossibilidade de nomeá-la.

A culpa ancestral, coletiva, que a casagrande simboliza, e o personagem encarna, esclarecia também o purgatório, o ritual que cumpria ele, de "expiação e esperança”, motivado por um anseio de salvação obscuro; a casa-grande explicava assim por que se voltava também à paisagem, ao grande-sertão, em busca de transcender sua condição histórica de patriarca, a qual havia principiado a negar com seu uniforme de "reles libré".

A casa-grande, ainda, que sintomaticamente só desapareceria com o fogo, com o próprio personagem, esta casa-grande da "a-a pique difícil fazenda do TortoAlto" era capaz de explicar até a conformação física de Tio Man'Antônio, sua parecença tão funda com ela, alto e torto como ela, e seu incômodo, ele que se entortava todo, como que alto demais, ao penetrar no sombrio solar ("Mas, ele, de cada vez, se curvava, de um jeito, para entrar, como se a elevada porta fosse acanhada e alheia, convidadamente, aos bons abrigos").

Estabelecida a culpa, estabelecido o contraste entre a casa-grande e o grandesertão, o contraste pois entre a história e o anseio de transcendê-la, estamos aptos a compreender o sentido do "surdo plano", da "enorme, feita fantasia".

O projeto, que revira a vida personagem, tem início na segunda parte do conto, a parte que inicia a narração propriamente dita, e que podemos chamar o fabuloso reino 
do faz-de-conta.

Passamos agora a uma paráfrase interpretativa, de acordo com nossa hipótese inicial, que atribui à casa-grande, enquanto símbolo de nosso passado colonial nada róseo, a causa do mal-estar do esfíngico patriarca, e que vê no grandesertão, essa paisagem de vocação metafísica, uma possibilidade de transcendência uma esperança de salvação.

Antes dela, cabe uma pequena digressão, pelo parentesco temático entre o conto que ora interpretamos e a novela integrante d'Estas Estórias, de 1969, saga deliciosa sobre a soberba, escrita em 1964 a pedido de José Olympio para fazer parte do livro Os Sete Pecados Capitais.

Em "Chapéus Transeuntes", título da saga, também identificamos um mal-estar geral. Nela porém é indiscutível a origem do desconforto do atormentado quatrocentãozinho que narra a história, Nestorzinho Leôncio Aquidabã Pereira Serapiães Dandrade, e que luta por subtrair a amada, Drininha, da estirpe orgulhosa encarnada pelo Vovô Barão, um homem "inconsertável, tal a sua torcedura", um homem que "parecia ser - a montanha indeclinável": o peso ou a maldição do sangue. Trata-se da soberba como herança de classe também, histórica, mas em ponto menor, herança de família.

\section{O IMPERATIVO ESTÉIICO}

Assim, se na primeira parte do conto, a parte pré-narrativa, vemos um fazendeiro, de passado incerto e certa "tenção" ("Vivia, feito tenção"), levar a vida subindo e descendo, diária e fervorosamente, uma montanha, rumo ora ao lugarejo próximo, ora à casa-grande no topo da colina, montado humildemente num humilde burrinho, com um vago sentimento de culpa e uma esperança vaga de salvação, e quase perdendo a vista, literalmente, com o contemplar e interrogar a paisagem feérica de "fundos e cumes" e seus "traiçoeiros altos-ebaixos", se nesta parte, pois, de compasso de espera, de sumário de inquietações, sentimos que algo está por sobrevir (é a "esperança”) e algo se purga (é a “expiação”), e que resumimos na idéia de ritual - na segunda parte um acontecimento desencadeia uma revolução na vida da personagem (2).

Morre sua mulher, Tia Liduína, e Tio Man'Antônio contraria as expectativas das filhas; "incôngruo", pratica luto aberto, abrindo a casa de cômodo em cômodo; numa espécie de epifania do tempo, que se lhe apresenta, agora, ao contemplar a paisagem, não mais "segmentadamente", "serial", mas de um só golpe, "na vislumbrança”, pegando-a pelas costas, pelos avessos - ele se redefine "inquebrantável", dispensando passado e futuro.

Com efeito, ao abrir de uma vez, de par em par, a casa-grande, como se fosse ela uma espécie de caixão estreito e opressivo, o personagem renasce, se metamorfoseia, tornando-se "outra espécie, decorosa, de pessoa”, metamorfose física e moral, a ponto de assemelhá-lo quase à paisagem montanhesa, à montanha encimada pelo céu, o rosto "fino [...] cinzento moreno [...] os olhos empalidecidamente azuis".

Consolando as filhas, respondendo a uma delas, Felícia ("Pai, a vida éfeita só de traiçoeiros altos-e-baixos? Não haverá, para a gente, algum tempo de felicidade, de verdadeira segurança?"), Tio Man' Antônio chega a sua divisa máxima: "Faz de conta, minha filha... Faz de conta...".

Esse achado se tornará, de lema, num passo capital do conto, em verdadeiro projeto, no "plano surdo" que passará a guiar toda a conduta do protagonista: “Ao revés, porém, Tio Man'Antônio concebia. 'Faça-se de conta!' - ordenou, em hora, mansozinho. Um projeto, de se crer e obrar, ele levantava. Um, que começaram".

\section{"Faça-se de conta!"}

Que projeto é este?

Que revolução será esta?

Podemos dizer que estamos, glosando Kant, diante de um imperativoestético, mas um imperativo que, buscando também se universalizar, em ato, em obra (não esque-

\footnotetext{
2 A morte súbita da mulher par ticipa, segundo Alfredo Bosi (1988), daquele "universo se mântico do 'de-repente'", tão vital aos personagens rosianos das Primeiras Estórias, fazendo-os passar do reino da ne cessidade ao reino da liberdade. No dizer poético do crítco: "No cinzento, o evento. A epifania" (p. 24).
} 
çamos a ambição exemplar do conto), não deixa de ser, em última instância, ético.

O faz-de-conta, esse imperativo estético que rege o mundo da carochinha, que é em suma o fundamento último do mundo da ficção, é a resposta que se dá ao peso da história, à nossa historicidade, à nossa precariedade, à transitoriedade das coisas, a resposta enfim à "nossa condição".

O imperativo estético (e ético), "Façase de conta!", esse fiat lux do mundo da criação, ao irromper como o fiat lux da criação de um novo mundo, vai inclusive reinterpretar o sentido do "nada".

Tudo se passa como se a falta do artigo definido no título - "Nada e a Nossa Condição" - estivesse já a indicar que, em vez de ponto final, o nada, com tal indefinição, deve ser visto sobretudo como ponto de partida, como o ponto de partida indefinido, mas inevitável a quem quer transcender a própria condição.

Trata-se portanto de uma reinterpretação positiva do nada. É como se a indefinição de partida, mais que brincadeira sobre a impossibilidade lógica de definir o nada, significasse, em verdade, a condição prévia da transcendência.

Empunhando essa bandeira da criação, Tio Man'Antônio põe mãos à obra, dando início a sua longae paradoxal curva de vida, uma história de despojamento e imponência, de desmaterialização e espiritualização absoluta ("de transparência em transparência”), e que terminará numa espécie de sagração do seu ser pelo fogo - uma história de despojamento e imponência, a assimilar a soberba montanha, e culminar na fundação do mito.

Tendo já se despojado da dor do luto, com aquela frase libertadora ("Faz de conta..."), começa, primeiro, despojando-se da paisagem, "desmanchando o aspecto do lugar”, desmanchando a realidade física da região, aplainando em campos e planícies as "rampas de serras".

Seu "surdo plano" veio então à luz consumar "uma enorme, feita fantasia".

Despojado da paisagem, Tio Man'Antônio despoja-se das filhas, ao comemorar festivamente, dando festa para casá-las, o primeiro ano de passamento da mulher.

Despojando-se mas crescendo a nossos olhos, prosperando mas continuando a trabalhar, orando e laborando-fazendo de conta, em sua linguagem, atingimos assim o apogeu do fabuloso reino do faz-de-conta.

\section{A REFORMA SOCIAL}

Nesta terceira parte do conto, radicalizase o despojamento do personagem, cujo "mais costumeiro gesto era o de como se largasse tudo de suas mãos, qualquer objeto". Próspero, no auge da prosperidade, "tudo se inestimava, porém, para Tio Man'Antônio”.

As "humanas fragilidades" faziam pensar numa "mor justiça”. Dizendo figurativamente, era como se o fazendeiro se voltasse agora para as humildes planícies, depois de tanto tempo voltado para a soberba montanha, "alta - como consequiência de nenhum ato".

De olho nas desproporções sociais, o protagonista despoja-se de suas riquezas, enviando-as às filhas e aos genros na cidade, despoja-se de suas terras, doando-as aos seus servos, junto com sua célebre divisa, procedendo a uma silenciosa reforma agrária, a "muito remexida história".

Se, com o "surdo plano" na segunda parte do conto, acompanhamos o nascimento do imperativo estético e sua transformação em obra, em princípio ético, agora, com a reforma agrária, assistimos à conversão desses mesmos princípios num princípio político, de organização da sociedade.

Em outras palavras, redefinida a paisagem física, após sua própria redefinição, física e moral, Tio Man'Antônio aprofundava seu projeto, redefinindo a paisagem humana e social.

Despojado de tudo e de todos, enfim, à exceção da casa-grande, donde regia o trabalho dos ex-servos, para que também prosperassem, mas ainda odiado "milenar e animalmente", porque "sempre majestade", foi se recolhendo e aquietando, deixando de interrogar a paisagem, "'acertando-se ao 




vazio e à redesimportância”, até a morte suave dos justos, "como se por um furo de agulha um fio".

\section{NASCIMENTO DO MITO}

Nesta última parte do conto, com a morte de Tio Man'Antônio, tomamos conhecimento da última cláusula do contrato que fez com seus servos, "as exigidas partes de um texto, sem decifração": o "rubro serão" - o qual coroa o movimento paradoxal de despojamento e imponência, desencadeado pelo "Faça-se de conta!", aquele imperativo do mundo da criação mas apto a criar um novo mundo, aquele imperativo estético que nascia para negar a ordem histórica, da casa-grande, da "nossa condição", e afirmar a natureza sobrenatural, metafísica, redentora, estórica, do grande-sertão.

Ao corpo e à casa, ateia-se-lhe fogo, provocando fogueira tão monumental que era como se a própria montanha, "tão vã e vagalhã", ardesse, "esplendissimamente".

Com o desaparecimento da trindade, personagem/casa-grande/montanha, consumidos no fogo purificador, Tio Man'Antônio se vê consagrado, convertido em "Destinado", elevado como foi, mas por obra pessoal, "alto" mas como "as conseqüências de mil atos".

Depois de ter feito de conta nada ter, despojado de tudo, fez de conta nada ser, despojando-se de seus próprios despojos. Fazendo de conta nada ser, chegava enfim ao Ser, sacrificado, consagrado.

Tio Man'Antônio chegava à condição de mito.

Aqui precisamos abrir um parêntese.

A paisagem, física e metafísica, do conto, como figuração da vida, não se fixa rigidamente num só sentido, não se alegoriza facilmente, digamos. Mais próximo do símbolo, o grande-sertão (3) aponta mais ou menos para três direções: 1) ora aponta para a vida perigosa, com seus "fundos e cumes", seus "traiçoeiros altos-e-baixos"; 2) ora aponta para a vida ordinária, com suas des-

Para ter idéia das múltiplas res sonâncias simbólicas do grande-sertão no universo rosiano ver a interpretação de fôlego de Davi ArrigucciJr. (1994) da obra-prima do escritor. 
proporções aparentemente naturais entre os humílimos rasos e as soberbas montanhas, "como conseqüências de nenhum ato"; 3) e ora aponta para a vida verdadeira, com seu alto exemplo, "sobre asas", sempre ameaçando ascender, transcender, "vanecer-se".

Essa mobilidade de sentido, esta feição simbólica da paisagem, que acompanha o desenvolvimento da personagem, sua história de despojamento e imponência, está presente também na representação vária da casa-grande. Podemos dizer que ela suporta quatro mudanças de fachada, cada uma das quais correspondendo a cada parte do conto. Assim temos: 1) a casa-grande espantosamente real do ritual de expiação e esperança; 2) o castelo "suspenso no pérvio" no fabuloso reino do faz-de-conta; 3) a casagrande freiriana, dada e avarandada, espécie de ilha ou farol "donde o mundo se fazia maior", e quando ele ruminava a reforma agrária em suas terras; e 4) com a morte do fazendeiro, no "rubro serão", a casa-grande espantosamente assombrosa, ou simplesmente Casa, sua última morada, no final grafada duas vezes, em maiúscula e mistério.

\section{O IDEALISMO ROSIANO}

Interpretando "Desenredo", de Tutaméia (1967), em que Jó Joaquim desenreda a história de sua volúvel amada, volúvel até no nome, que não se fixa, Livíria, Rivília ou Irlívia, em que Jó Joaquim “criava nova, transformada realidade, mais alta”, Davi Arrigucci Jr. (1993) localiza o "idealismo rosiano".

Jó Joaquim, contra a evidência dos fatos, contra a realidade objetiva, ele, que fora duas vezes enganado por ela, refaz a vida da amada, apagando seus adultérios, purificando-a inteiramente, criando uma realidade nova, e na qual vêm todos a crer, o povo, ele mesmo e até a própria mulher.

O paradoxal é que dá certo a nova estória, ao contrário da história real, que dá errado...

Contra a mimese realista, é como se Rosa postulasse a verdade da imaginação, a verdade poética, para a qual, aristotelicamente, o inverossímil, porque crível, alcança o estatuto de verdadeiro.

Do mesmo modo, com seu imperativo estético, Tio Man' Antônio cria outra realidade, uma "enorme, feita fantasia". Do princípio da ficção, da esfera da estética, vemos, pouco a pouco, nascer toda uma nova ordem, ética, social, política e econômica, desenredando, como Jó Joaquim, um enredo histórico opressivo, "alicerçado fundo" na história do país, transcendendoo, enfim, pela imaginação criadora, pela verdade da poesia.

\section{MATERIALISMO ROSIANO}

Sabemos que a grande literatura problematiza, mas não resolve. Por isso não tomemos o destino generoso de Tio Man'Antônio, transcendente, como receituário político. O escritor não era ingênuo, e, ademais, seu apoliticismo, seu apartidarismo, melhor dizendo, por convicção e por posição, era por demais conhecido, como patenteia a célebre entrevista a Günter Lorenz em 1965 (Rosa, 1979). Não se esperasse dele nunca nenhum pronunciamento em defesa de causa alguma. Não ia falar das Ligas Camponesas de seus dias, então recém-liquidadas pelo golpe militar de 64, nem falaria nos nossos do Movimento dos Sem-Terra. Mas sua responsabilidade de escritor, seu compromisso com o destino humano, e sobretudo sua solidariedade essencial com os pobres, com os oprimidos, com sua visão de mundo mítica, digamos, para não encompridar a história, não o deixaram alheio às tremendas injustiças sociais que nos sufocam.

Essa solidariedade essencial não se traduz, porém, apenas na adesão à perspectiva dos humildes; traduz-se também, e principalmente, no plano literário mesmo. Na contramão de Graciliano, para recuperar a fecunda oposição de Alfredo Bosi, sua antimimese da aridez, com sua exuberância estilística, com seu transbordamento poético, com sua fartura de invenções lin- 
güísticas, também mimetiza, e mimetiza, curiosamente e paradoxalmente, uma utopia, uma não-fala, uma fala original que nunca existiu nem existirá, mas que existiria em potência no homem. Eis o que verdadeiramente imita sua literatura.

Poderão me objetar que se trata de invenção, de invenção pura, e não de mimese, então... Mas que invenção é essa em que se reconhece uma humanidade mais alta e mais funda? A fala original, a não-fala como utopia, não deixa assim de mimetizar, porque a potencializa, uma humanidade que o escritor reconhece em germe, em estado de pré-história.

É desconcertante e faz cada vez mais meditar a inesgotável riqueza poética (4) que escavou essa literatura extraordinária de um ambiente humano e natural tão árido e miserável. Além de dar voz aos que não a têm (5), a poetização, em alto sentido, do grande-sertão, de um mundo sabidamente condenado a perecer nas mãos brutais do progresso, permite entrever a posição social de sua prosa.

Noutras palavras, é preciso levar a sério hoje, nestes tempos de progresso pelo progresso, cada vez mais espanado, sua relação política com a linguagem. O "reacionário" da língua, como se autodefiniu, já via afinidades perigosas entre os donos do progresso e seus adversários, os progressistas.

Imitação de uma utopia, de uma fala original, de uma fala essencial mas potencialmente humana, a fala literária do grande escritor nos ensina que, antes do sertão virar mar, cabia transformá-lo no que era, porque podia ser, um mar de poesia.
4 Parauma compreensão forma do lirismo em Rosa, ver Schwarz (1981).

5 Ver instigante comentário de Hansen sobre a entrevista de Rosa a G. Lorenz (1979)

\section{BIBLIOGRAFIA}

ARRIGUCCI JR., Davi. "Métodos e Técnicas de Análise e Interpretação da Obra literária", curso de pós-graduação na FFLCH-USP, 1ㅇsemestre, 1993.

. "0 Mundo Misturado - Romance e Experiência em Guimarães Rosa", in Novos Estudos Cebrap, no 40,

1994.

BOSI, Alfredo. “Céu, Inferno", in Céu, Inferno. São Paulo, Ática, 1988.

CANDID0, Antonio. "0 Homem dos Avessos", in Tese e Antítese. 3e ed. São Paulo, Nacional, 1978.

COUTINHO, Eduardo F. (org.). Guimarães Rosa - Fortuna Crítica. 2a ed. Rio de Janeiro, Civilização Brasileira, 1991.

HANSEN, João Adolfo. "A Imaginação do Paradoxo", in Arte em Revista, no 2. São Paulo, Kairós, 1979.

ROSA, Guimarães. Grande Sertão: Veredas. São Paulo, Abril Cultural, 1983.

Primeiras Estórias. 14e ed. Rio de Janeiro, Nova Fronteira, 1985.

Tutaméia. 6a ed. Rio de Janeiro, Nova Fronteira, 1985.

Estas Estórias. 2a ed. Rio de Janeiro, José Olympio, 1976.

. "Literatura e Vida - um Diálogo de Günter W. Lorenz com João Guimarães Rosa", in Arte em Revista,

no 2. São Paulo, Kairós, 1979.

SCHWARZ, Roberto. "Grande Sertão: a Fala", in A Sereia e o Desconfiado. 2a ed. São Paulo, Paz e Terra, 1981. 